\title{
BENZYLCHLOROCARBENE: UV ABSORPTION SPECTRUM, KINETICS FOR 1,2-H MIGRATION AND MECHANISM FOR REACTION WITH ACETIC ACID AS DETERMINED BY COMBINED CONTINUOUS AND LASER-FLASH PHOTOLYSIS
}

\author{
R. BONNEAU
}

UA 348 du CNRS, Laboratoire de Chimie Physique A, Université de Bordeaux I, 33405 Talence (France)

M. T. H. LIU, R. SUBRAMANIAN and B. LINKLETTER

Department of Chemistry, University of Prince Edward Island, Charlottetown, P.E.I., Canada C1A 4P3

\section{D. R. STEVENS}

Department of Chemistry, University of Southampton, SO9 5NH, England

(Received 15 September, 1989; in final form 15 November, 1989)

The UV absorption spectrum of benzylchlorocarbene, generated by laser flash photolysis of 3-chloro-3benzyldiazirine, has been observed in the $290-330 \mathrm{~nm}$ range. The lifetime of this species, $18 \mathrm{~ns}$ at $25^{\circ} \mathrm{C}$, is determined by the rate of the 1,2-H migration to produce chlorostyrenes. Quenching rate constants of this carbene by acetic acid and tetramethylethylene have been measured. Comparison of this kinetic data with the quantitative analysis of the products obtained under continuous irradiation gives further insight into the mechanisms of carbene-acetic acid reactions.

KEY WORDS: Carbene, 1,2-H migration, laser-flash photolysis.

\section{INTRODUCTION}

The most common rearrangement reaction of alkyl substituted carbenes is the migration of a hydrogen atom to the carbene centre which affords an alkene.

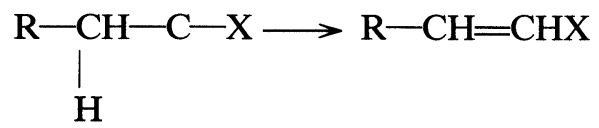

When $\mathrm{X}$ is a chlorine atom and in the presence of reactants such as olefins, alcohols or acids, this reaction is in competition with reactions of the carbene with either the ethylenic double bond to give cyclopropanes or the $\mathrm{O}-\mathrm{H}$ bond to give ethers or esters. ${ }^{1}$ The relative amount of the products obtained under continuous irradiation of precursors for this type of carbene (such as 3-chloro-3-benzyldiazirine, 1, which 
gives the benzylchlorocarbene, 2) has been measured as a function of the concentration of several olefins. ${ }^{2}$ From these studies, it was concluded that the mechanism of the addition reaction of carbenes to olefins involves an intermediate complex from which both rearrangement and cyclopropanation reactions are possible. The formation of this complex could be reversible as suggested by Turro and Moss ${ }^{3}$ to account for the negative activation energies observed for the addition of $\mathrm{Ph}-\mathrm{C}-\mathrm{Cl}$ to trimethyl- and tetramethyl-ethylene. However, theoretical calculations by Houk and Rondan ${ }^{4}$ provided no evidence for a carbene-alkene complex. We have recently reported a laser flash photolysis study ${ }^{5}$ of the system "Benzylchlorocarbene + tetramethylethylene" and confirmed the existence of this complex but we could not give definitive conclusion concerning the question of the reversibility of its formation.

In the present paper, we wish to examine the photolysis of 1 in the presence of acetic acid under both continuous irradiation and laser-flash-photolysis conditions in order to get information about the mechanism for the reaction of this acid with carbene 2 and, more precisely, about the existence (or the non-existence) of an intermediate such as the ion-pair previously suggested. ${ }^{6}$

\section{EXPERIMENTAL SECTION}

3-chloro-3-benzyldiazirine, 1 , was prepared by the Graham's method ${ }^{7}$ and purified by chromatography on 60-200 mesh silica gel. Pyridine was distilled over $\mathrm{CaH}_{2}$ which has been shown to be superior to other desiccants, including sodium. ${ }^{8}$ Absence of chlorostyrene prior to photolysis was confirmed by NMR spectroscopy. Continuous irradiation at $25^{\circ} \mathrm{C}$ was carried out with 3500 -UV lamps in a Rayonet photoreactor until all the diazirine $(0.03 \mathrm{M}$ in isooctane with various amounts of acetic acid) was destroyed. The reaction mixture was worked-up by diluting with water and extracting repeatedly with carbon tetrachloride. The combined extracts were washed with $\mathrm{NaHCO}_{3}$ solution, water and then dried. The products were analyzed on a Varian Vista 6000 gas chromatography fitted with a $6 \mathrm{ft} \times 0.125$ in. stainless steel column packed with CSP-20M. The G.C. traces were calibrated by using authentic samples of the reaction products. Peak area were integrated with a HP-3390A recorder. The laser-flash-photolysis set-up uses a crossed-beams arrangement. The sample in a $10 \times 10 \mathrm{~mm}$ cell was excited at $355 \mathrm{~nm}$ by single light pulses $(200 \mathrm{ps} ; 5-30 \mathrm{~mJ})$ provided by a frequency tripled mode-locked Nd-YAG laser (Quantel). The detection system (pulsed Xe-arc, monochromator, photomultiplier and a Tektronix 7912 transient recorder) has a response time around $5 \mathrm{~ns}$.

\section{RESULTS}

\subsection{Continuous Irradiation}

Photolysis of 1 in isooctane yielded Z- and E- $\beta$-chlorostyrenes in a 3:13 ratio. Addition of acetic acid to the photolysis medium gave 1-chloro-2-phenylacetate ${ }^{6}$ as 
well as the Z- and E- $\beta$-chlorostyrenes. The acetate formed was found to increase with increasing the acetic acid concentration whereas the amount of $\beta$-chlorostyrenes decreases, indicating that these products are formed by two competitive processes such as:

$$
\begin{gathered}
\text { Carbene } \longrightarrow \text { Styrenes } \\
\text { Carbene }+\mathrm{AcOH} \longrightarrow \text { Acetate }
\end{gathered}
$$

However, a plot of the ratio [Acetate]/[Styrenes] (see Table 1) as a function of $[\mathrm{AcOH}]$ shows a pronounced curvature indicating that the reaction mechanism is not a simple competition between reactions (1) and (2) since, with these two elementary processes, the ratio [Acetate]/[Styrenes] would be linear with respect to $[\mathrm{AcOH}]$. Furthermore, as the acetic acid concentration increases, the $\mathrm{Z} / \mathrm{E}$ ratio increases up to values larger than one and when deuterated acetic acid is used as solvent, about $20 \%$ of the chlorostyrenes contained deuterium, indicating that there are at least two routes for the formation of the chlorostyrenes.

Table 1 Products distribution for the photolysis of 1 in isooctane, at $25^{\circ} \mathrm{C}$, as a function of $\mathrm{AcOH}$ concentration

\begin{tabular}{lllllllll}
\hline [AcOH] & 0.1 & 0.2 & 0.4 & 0.8 & 1.2 & 1.8 & 2.4 & 3.0 \\
\hline [Acetate] & 0.86 & 1.04 & 1.26 & 1.46 & 1.56 & 1.57 & 1.62 & 1.57 \\
\hline [Styrenes] & 0.58 & 0.75 & 0.94 & 1.04 & 1.07 & 1.06 & 1.04 & 1.17 \\
\hline
\end{tabular}

\subsection{Laser-Flash-Photolysis}

Laser-flash-photolysis of 1 in isooctane in the presence of pyridine produces a transient species with an absorption band peaking around $380 \mathrm{~nm}$. This transient is not present in the absence of pyridine and is attributed to pyridinium ylide 3 .

Plot of the observed pseudo-first-order rate constants for the growth of the absorption at $370 \mathrm{~nm} v s$ [pyridine] is linear. The slope gives the rate constant for reaction of the carbene with pyridine, $k_{y}=(7.5 \pm 0.5) \times 10^{9} \mathrm{M}^{-1} \mathrm{~s}^{-1}$, and the intercept (extrapolation to [pyridine] $=0$ ) yields the reciprocal lifetime of the carbene 2 which is determined by the rate constant for $1,2-\mathrm{H}$ shift, $k_{i}=(6.0 \pm 0.5) \times 10^{7} \mathrm{~s}^{-1}$ at $25^{\circ} \mathrm{C}$.

The UV spectrum of a solution of diazirine 1 is isooctane consists of a structured absorption band in the 310 to $370 \mathrm{~nm}$ region, with low extinction coefficients, and a second one in the 220-290 nm range, very poorly structured, broad and intense. Transient absorption measurements are possible in the window $290-330 \mathrm{~nm}$ between these two bands. In the 305-330 $\mathrm{nm}$ region, a transient absorption appears within the response time of our analytical system (i.e. within the 3 ns following the $200 \mathrm{ps}$ excitation pulse) and decays to zero with a lifetime around $18 \mathrm{~ns}$. In the $295-305 \mathrm{~nm}$ range, a permanent (or very long-lived) absorption remains after the decay of the species with a $18 \mathrm{~ns}$ lifetime (see Figure 1a). The intensity of this absorption increases as the wavelength decreases and, at $290-295 \mathrm{~nm}$, the absorption remains nearly constant after the initial jump. The transient absorption is clearly due to two species 


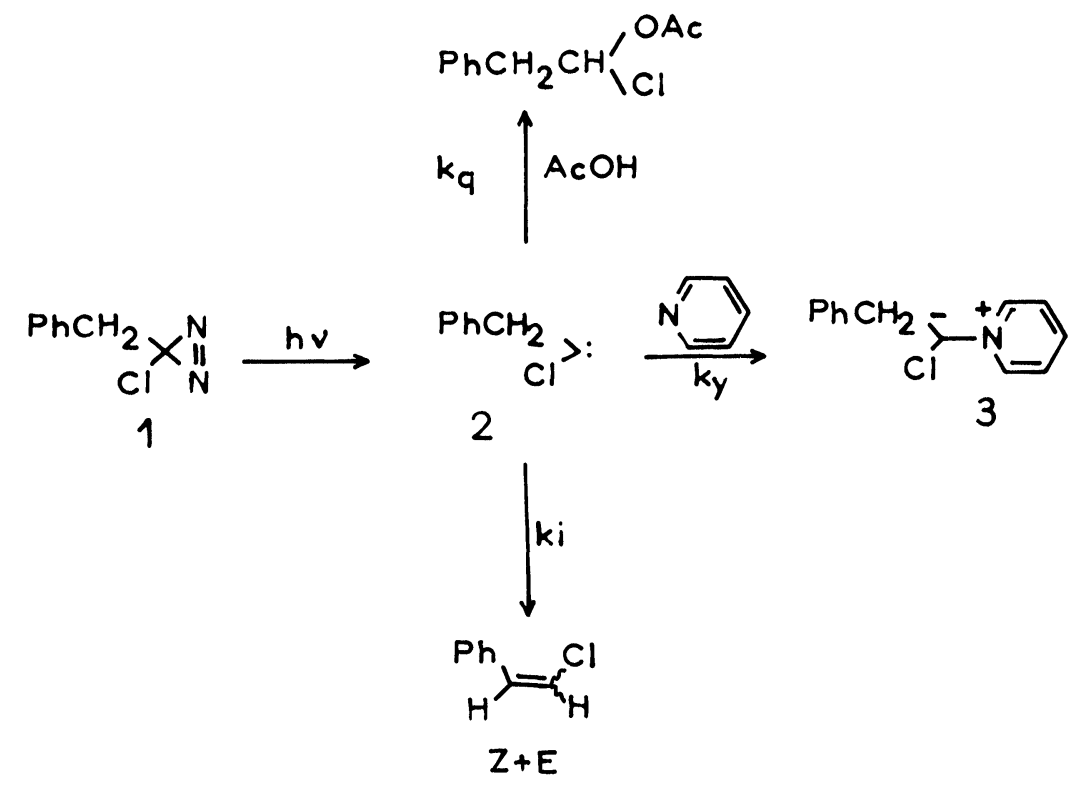

Scheme 1

with the first one ( $\tau \approx 18 \mathrm{~ns}$ ) being the precursor of the second since, when a reactant is added to the solution, the decrease in the lifetime of the first species is accompanied by a decrease in the amount of the second one (see Figure 1b). The absorption spectra of these species (Figure 2) are respectively given by the transient absorptions measured immediately (i.e. $3 \mathrm{~ns}$ ) after the excitation and after the complete decay of

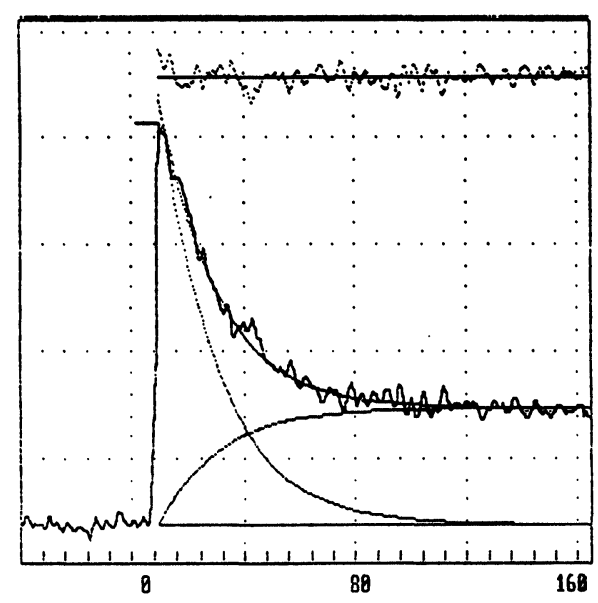

(a)

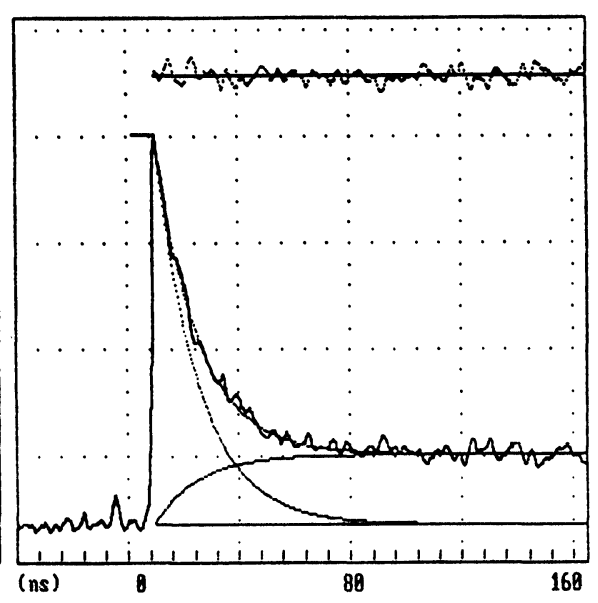

(b)

Figure 1 Transient absorption curve recorded at $297 \mathrm{~nm}$ and analysed as the sum of the absorption two transient species (dotted lines). The upper trace represents the difference between the calculated sum and the experimental trace. The decrease of the amount of the second species which accompanies the shortening of the lifetime of the first one upon the addition of acetic acid, shown in (b), indicates that the second species is formed from the first one. 


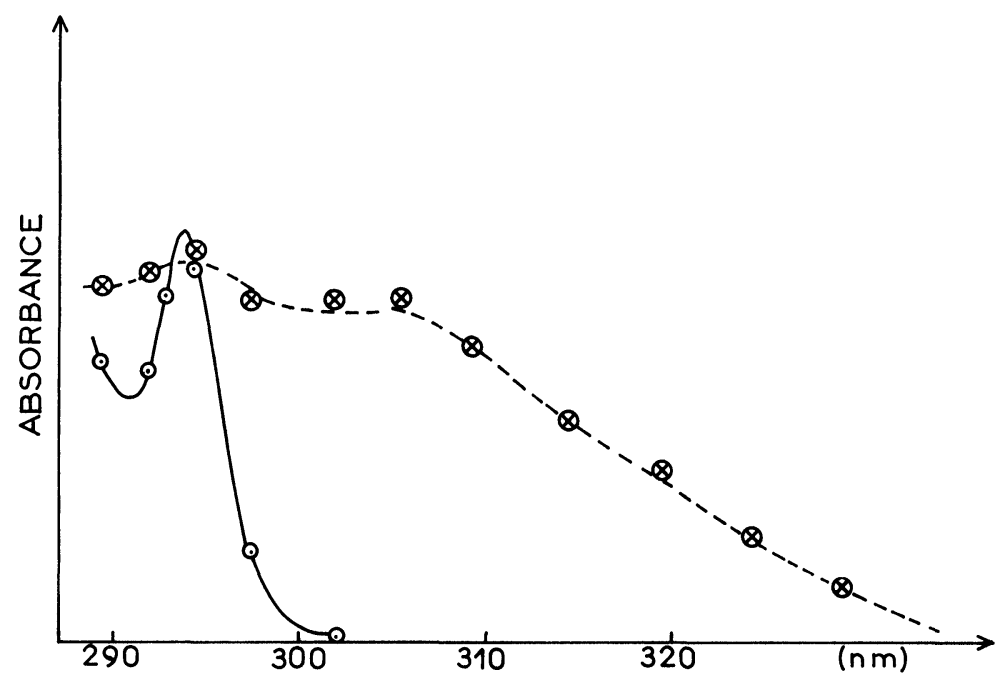

Figure 2 Absorption spectra of the benzylchlorocarbene, 2 (dashed line) and of the $\beta$-chlorostyrene (full time) recorded respectively at 3 and 100 nanoseconds after the excitation.

the first species (i.e. $100 \mathrm{~ns}$ after the excitation) since the correction which should be made to account for the diazirine bleaching is considered to be negligible. The second species is most probably the $\beta$-chlorostyrene, the first absorption band of which lies around $295 \mathrm{~nm}$. The first species, with a broad absorption over the 290-320 $\mathrm{nm}$ region, is assigned to the benzylchlorocarbene, 2 , on the basis of the agreement between the rate constants for its decay measured at $300 \mathrm{~nm}(5.4 \pm 0.2) \times 10^{7} \mathrm{~s}^{-1}$ and for the growth of the pyridinium ylide $(6.0 \pm 0.5) \times 10^{7} \mathrm{~s}^{-1}$, measured at $370 \mathrm{~nm}$ and extrapolated to [pyridine] $=0$.

The rate constant for the quenching of the carbene by acetic acid was determined from the rate of the carbene decay, $k_{d}=k_{i}+k_{q}(\mathrm{AcOH}]$, measured at $310 \mathrm{~nm}$ as a function of $[\mathrm{AcOH}]$. Least squares analysis of six measurements for $[\mathrm{AcOH}] \mathrm{ranging}$ from 1 to $15 \mathrm{mM}$ gives: $k_{q}=(9.61 \pm 1.0) \times 10^{8} \mathrm{M}^{-1} \mathrm{~s}^{-1}$.

\section{DISCUSSION}

We have mentioned above that a simple competition between reactions (1) and (2) cannot account for the product distribution and that a fraction of the chlorostyrenes is produced after interaction of the carbene with AcOD. ${ }^{6}$ This leads us to consider the following mechanism where, for kinetic treatments, it is not necessary to define precisely the nature of the complex.

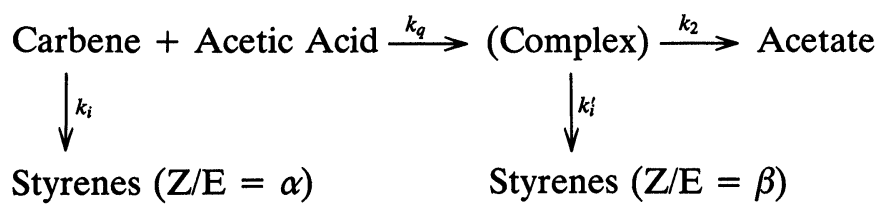

Scheme 2 
With notations represented in Scheme 2, the yields of formation of the acetate, $\phi_{A}$, and of the styrenes, $\phi_{S}$, are:

$$
\begin{gathered}
\phi_{A}=\left\{k_{q}[\mathrm{AcOH}] /\left(k_{i}+k_{q}[\mathrm{AcOH}]\right)\right\} \cdot\left\{k_{2} /\left(k_{2}+k_{i}^{\prime}\right)\right\} \\
\phi_{S}=k_{i} /\left(k_{i}+k_{q}[\mathrm{AcOH}]\right)+\left\{k_{q}[\mathrm{AcOH}] /\left(k_{i}+k_{q}[\mathrm{AcOH}]\right)\right\} \cdot\left\{k_{i}^{\prime} /\left(k_{2}+k_{i}^{\prime}\right)\right\}
\end{gathered}
$$

Then the ratio of these yields gives:

$$
\left[\text { Styrene] } /\left[\text { Acetate] }=\left(k_{i}^{\prime} / k_{2}\right)+\left(k_{i} / k_{q}\right) \times\left\{\left(k_{2}+k_{i}^{\prime}\right) / k_{2}\right\} \times(1 /[\mathrm{AcOH}])\right.\right.
$$

From data obtained under continuous irradiation at $25^{\circ} \mathrm{C}$, the plot of the ratio [Styrenes]/[Acetate] vs 1/[AcOH], shown in Figure 3, yields an intercept $\left(k_{i}^{\prime} / k_{2}\right)=$ 0.60 from which one gets $k_{2} /\left(k_{2}+k_{i}^{\prime}\right)=0.625$ and $k_{i}^{\prime} /\left(k_{2}+k_{i}^{\prime}\right)=0.375$. The slope, equal to 0.065 , leads to $k_{i} / k_{q}=0.040$.

The changes of the $\mathrm{Z} / \mathrm{E}$ ratio as a function of $[\mathrm{AcOH}]$ can be analyzed as follows. The 1,2 $\mathrm{H}$-shift in the "free carbene" produces the $\mathrm{Z}$ and $\mathrm{E}$ isomers of $\beta$-chlorostyrene with a $Z / E$ ratio, $\alpha=0.23$. The yield of $Z$ and $E$ chlorostyrenes formed by this way being $\phi_{s}=k_{i} /\left(k_{i}+k_{q}[\mathrm{AcOH}]\right)$, the amounts of $\mathrm{Z}$ and $\mathrm{E}$ isomers are $\phi_{s} \alpha /(\alpha+1)$ and $\phi_{s} /(a+1)$ respectively.

The ratio, $\beta$, of the chlorostyrenes isomers formed from the "Complex" may be quite different since, firstly, the 1, $2 \mathrm{H}$-shift may be perturbed by the "complexation"

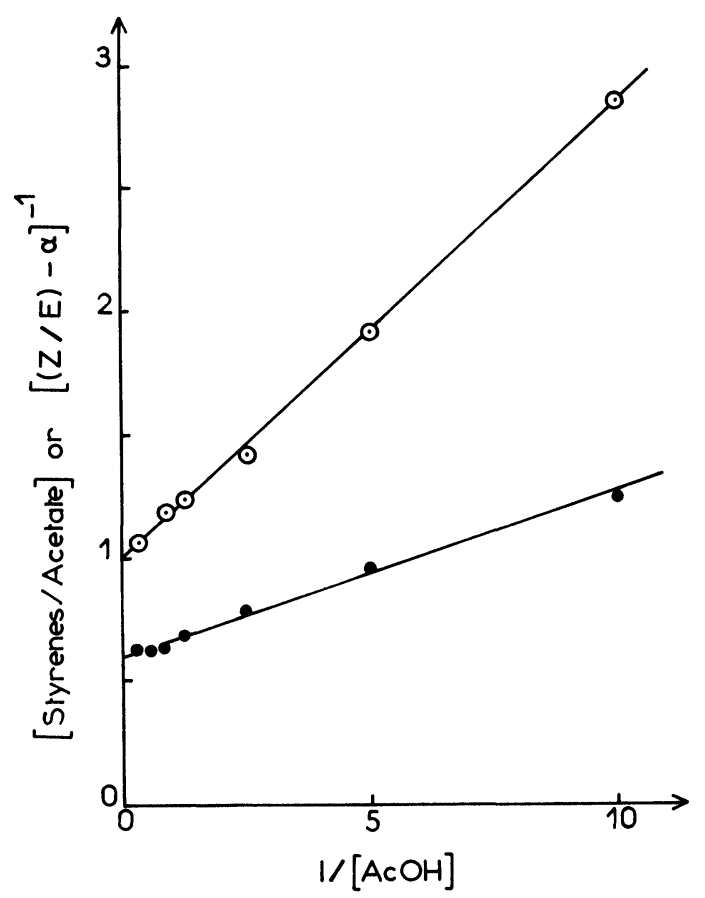

Figure 3 Analysis of the effect of acetic acid on the distribution of the products obtained after continuous irradiation. The analytical expressions for the ratio [Styrene]/[Acetate] and for the change in the relative amounts of $\mathbf{Z}$ and $\mathrm{E}$ chlorostyrenes isomers (open circles) are given in text. 
and, secondly, the incorporation of deuterium in $20 \%$ of the styrene products when the reaction is carried out in deuterated acetic acid indicates that (at least) one other mechanism must be effective to produce chlorostyrenes. The yield of chlorostyrenes formed from the complex is $\phi_{s}^{\prime}=k_{q} \cdot R^{\prime \prime}[\mathrm{AcOH}] /\left(k_{i}+k_{q}[\mathrm{AcOH}]\right)$, with $R^{\prime \prime}=k_{i}^{\prime} /\left(k_{2}+k_{i}^{\prime}\right)$, and the amounts of $\mathrm{Z}$ and $\mathrm{E}$ isomers are respectively $\phi_{s}^{\prime} \beta /(\beta+1)$ and $\phi_{s}^{\prime} /(\beta+1)$.

$$
\text { Then, } \begin{aligned}
\mathrm{Z} / \mathrm{E} & =\left\{\left[\phi_{s} \alpha /(\alpha+1)\right]+\left[\phi_{s}^{\prime} \beta /(\beta+1)\right]\right\} /\left\{\left[\phi_{s} /(\alpha+1)\right]+\left[\phi_{s}^{\prime} /(\beta+1)\right]\right\} \\
& =\left[\alpha(\beta+1) \phi_{s}+\beta(\alpha+1) \phi_{s}^{\prime}\right] /\left[(\beta+1) \phi_{s}+(a+1) \phi_{s}^{\prime}\right]
\end{aligned}
$$

This rearranges to:

$$
1 /(\mathrm{Z} / \mathrm{E}-\alpha)=1 /(\beta-\alpha)+k_{i}(\beta+1) /\left\{(\beta-\alpha)(a+1) k_{q} \cdot R^{\prime \prime}[\mathrm{AcOH}]\right\}
$$

With $\alpha=0.23$, the plot of $1 /(\mathrm{Z} / \mathrm{E}-\alpha)$ vs $1 /(\mathrm{AcOH})$ gives a straight line (see Figure 3 ) with an intercept $1 /(\beta-\alpha)=1$ from which one gets $\beta=1.23$ and a slope equal to 0.185 yielding $k_{i} / k_{q}=0.038$.

Due to the complexity of the procedure used for the quantitative analysis of the products formed under continuous irradiation, the uncertainty on the [Acetate]/ [Styrene] and $\mathrm{Z} / \mathrm{E}$ ratios is estimated to be at least $\pm 15 \%$ so that the accuracy on the ratio $k_{i} / k_{q}$ would be around $\pm 15 \%$ for the determination from the plot of [Styrenes] $/$ [Acetate) vs $1 /[\mathrm{AcOH}]$ and $\pm 25 \%$ when extracted from the plot of $1 /(\mathrm{Z} / \mathrm{E}-\alpha) v s$ $1 /[\mathrm{AcOH}]$. In the laser-flash photolysis experiments, the value $k_{i}=(5.4 \pm 0.2) \times 10^{\prime}$ $\mathrm{s}^{-1}$ is well defined because it has been measured many times as a function of many parameters. The error on $k_{q}$ is much larger because the range of $(\mathrm{AcOH}]$ which can be used to study the decrease of the carbene lifetime upon addition of acetic acid is very limited since we cannot use "high" $[\mathrm{AcOH}]$ yielding carbene lifetime shorter than $10 \mathrm{~ns}$. The uncertainty is estimated to be $\pm 25 \%$ in this case. Therefore the maximum ranges of value for $k_{i} / k_{q}$ are: $0.043-0.077$ from laser flash photolysis measurements, $0.028-0.048$ from the Z/E ratio and 0.034-0.046 from the [Styrenes]/[ Acetate] ratio. The fact that a common value for $k_{i} / k_{q}$ determined by these three independent methods can be found between 0.043 and 0.046 strongly supports the mechanisms presented in Scheme 2.

We can now examine the possible nature(s) of the "complex." For a better visualisation of the rearrangements leading to the products, deuterated acetic acid is used in the schemes.

i) Protonation of the carbene by the acid would result in the formation of an ion-pair (I) as intermediate complex. ${ }^{6}$ Such an ion-pair can collapse to give the acetate as product or, in a reverse acid-base reaction, the $\mathrm{AcO}^{-}$can abstract a proton on the benzylic carbon to give $\mathrm{PhCH}=\mathrm{CDCl}$ and $\mathrm{AcOH}$.

This simple mechanism cannot account for the fact that, when the reaction is conducted in $\mathrm{AcOD},{ }^{6}$ the ratio $[\mathrm{PhCH}=\mathrm{CHCl}] /[\mathrm{PhCH}=\mathrm{CDCl}]$ is equal to 4 . Then it can be assumed that a rapid 1,2-H shift occurs in the cationic moiety of the ion-pair leading to the ion-pair (Ib). This second ion-pair should give, by reverse acid-base reaction, a mixture of $\mathrm{PhCH}=\mathrm{CHCl}$ and $\mathrm{PhCH}=\mathrm{CDCl}$ but it would give in addition a second adduct, with the acetate on the benzylic carbon, which is not observed. 
<smiles>[2H]C(=O)OC([2H])(Cl)C(C)c1ccccc1</smiles><smiles>[2H]C(=O)O[C@@]([2H])(Cl)C(c1ccccc1)c1ccccc1</smiles><smiles>[2H]/C(Cl)=C\c1ccccc1</smiles><smiles>[AlH2]</smiles><smiles>[2H]C(Cl)C(OC(C)=O)c1ccccc1</smiles><smiles>CCCCC</smiles><smiles>[2H]C(Cl)([CH-]OC(C)=O)C(C)C</smiles><smiles>ClC=C(c1ccccc1)c1ccccc1</smiles>

\section{[ Ib]}

Scheme 3

ii) An alternative mechanism involves the attachment of the carbene to the carboxyl group of the acid to give an ylide type complex (II) followed either by $1,2-\mathrm{H}$ migration and decomposition of the ylide into AcOD and $\mathrm{PhCH}=\mathrm{CHCl}$ or by a rearrangement to the acetate. This hypothesis is substantiated by the fact that $1,2-\mathrm{H}$ migration has been demonstrated to occur within the ylide formed from the reaction of carbene 2 and pyridine. ${ }^{5}$

However, 1,2-H migration to a negatively charged carbon is usually not a fast and easy process: the pyridinium ylide obtained from carbene 2 has a long life-time and reaction products resulting from the rearrangement of $\mathrm{Ph}-\mathrm{CH}_{2}-\mathrm{CH}_{2}^{-}$in $\mathrm{Ph}-{ }^{-} \mathrm{CH}-\mathrm{CH}_{3}$ by $1,2-\mathrm{H}$ shift have not been observed whereas they were identified for the $\mathrm{Ph}-\mathrm{C}_{3} \mathrm{H}_{6}-\mathrm{CH}_{2}-$ and for $\mathrm{Ph}-\mathrm{C}_{4} \mathrm{H}_{8}-\mathrm{CH}_{2}-$ carbanions which rearrange respectively into $\mathrm{Ph}-{ }^{-} \mathrm{CH}-\mathrm{C}_{3} \mathrm{H}_{7}$ and $\mathrm{Ph}-{ }^{-} \mathrm{CH}-\mathrm{C}_{4} \mathrm{H}_{9}$ by 1,4 and $1,5-\mathrm{H}$ shift. ${ }^{9}$

Furthermore, the reaction in AcOD gives significantly more chlorostyrenes under photolytic conditions than in thermolysis and the ratio $[\mathrm{PhCH}=\mathrm{CHCl}] /[\mathrm{PhCH}=$ $\mathrm{CDCl}$ ], equal to 4 under photolysis, is only 1 in thermolysis. ${ }^{6}$ Thus, it seems that,<smiles>[2H]C(=O)OC([2H])(Cl)C([2H])c1ccccc1</smiles>

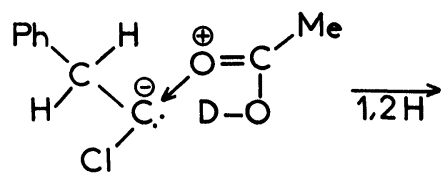<smiles>[2H]OC(C)=O</smiles> 


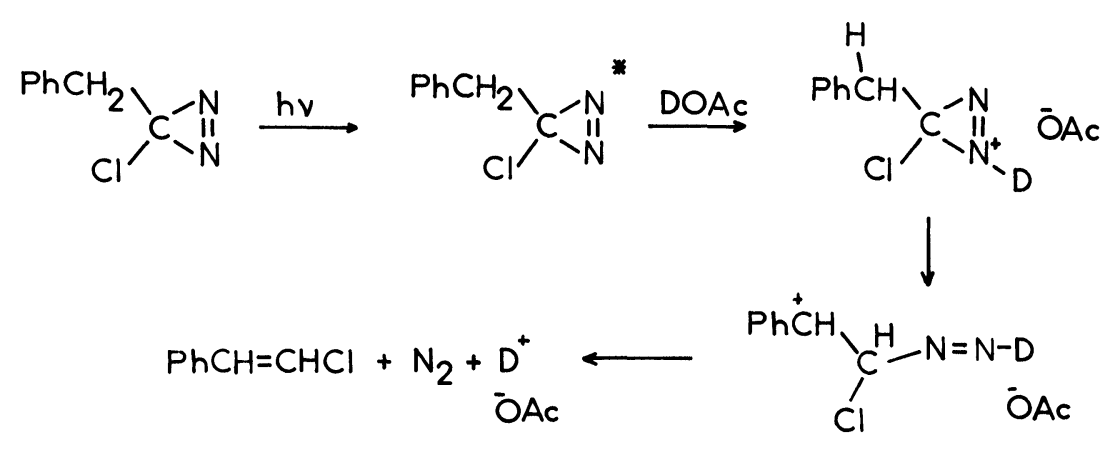

Scheme 5

with high acetic acid concentration at least, a significant route to non-deuterated chlorostyrenes exists. A mechanism involving the protonation of the excited diazirine (see Scheme 5) has been proposed ${ }^{1}$ but the quite short lifetime of the excited diazirine, indicated by the failure to detect its fluorescence and by its unit quantum yield of decomposition, seems to rule out this mechanism at low acetic acid concentrations.

Finally, the rate constant for the quenching of the carbene 2 by tetramethyl ethylene, TME, to form cyclopropane has been determined by measuring the rate of decay of the carbene absorption at $310 \mathrm{~nm}$ as a function of [TME]. Least squares analysis of measurements at $22^{\circ} \mathrm{C}$, for [TME] ranging from 4 to $25 \mathrm{mM}$, gave $k_{q}=$ $(7.9 \pm 0.7) \times 10^{8} \mathrm{M}^{-1} \mathrm{~s}^{-1}$. It has been previously believed that the reaction of carbene and $\mathrm{AcOH}$ was so rapid that other trapping reactions were not competitive. It is clear now that this is not true. For example, when 1 was irradiated in a mixture of $\mathrm{TME}$ and $\mathrm{AcOH}$, the acetate and cyclopropane were produced in nearly equal amounts as well as traces of chlorostyrenes. ${ }^{6}$

\section{References}

1. M. T. H. Liu, I. D. R. Stevens and M. T. H. Liu (Ed.), Chemistry of Diazirines (C.R.C. Press, Boca Raton, Fl., 1987).

2. M. T. H. Liu, R. V. Suresh, N. Soundararajan and E. G. Vessey, J. Chem. Soc., Chem. Comm. 12 (1989).

3. (a) I. R. Gould, N. J. Turro, J. A. Butcher Jr., C. Doubleday Jr., N. P. Hacker, G. F. Lehr, R. A. Moss, D. P. Cox, W. Guo, R. C. Munjal, L. A. Perez and M. Fedorynski, Tetrahedron 41, 1987 (1985). (b) R. A. Moss, W. Lawrynowicz, N. J. Yurro, I. R. Gould and Y. Cha, J. Am. Chem. Soc. 108, 7028 (1986).

4. K. N. Houk, N. G. Rondan and J. Mareda, J. Am. Chem. Soc. 106, 4291 and 4293 (1984).

5. M. T. H. Liu and R. Bonneau, J. Am. Chem. Soc. submitted for publication.

6. M. T. H. Liu, N. H. Chisthi, M. Tencer, H. Tomioka and Y. Izawa, Tetrahedron 40, 887 (1984).

7. W. H. Graham, J. Am. Chem. Soc. 87, 4396 (1965).

8. D. R. Burfield, R. H. Smithers and A. S. C. Tan, J. Org. Chem. 46, 629 (1981).

9. A. Maercker and M. Passlack, Chem. Ber. 115, 540 (1982). 